\title{
Psychological well-being of the Elderly in Nigeria
}

\author{
Oluwabunmi Grace Ibitoye ${ }^{1}$ \\ Olutobi Adekunle Sanuade ${ }^{2}$ \\ Ayo Stephen Adebowale ${ }^{3}$ \\ Olusola Ayeni ${ }^{3}$
}

\author{
${ }^{1}$ Nigeria Social Insurance Trust Fund, Abuja, Nigeria \\ ${ }^{2}$ Regional Institute for Population Studies \\ University of Ghana Accra, Ghana \\ ${ }^{3}$ Department of Epidemiology \& Medical Statistics \\ Faculty of Public Health \\ College of Medicine, University of Ibadan \\ Ibadan, Nigeria
}

${ }^{1}$ Corresponding Author: email: bumtoye@gmail.com

\begin{abstract}
In Nigeria, growing old is usually feared because of the multi-faceted problems associated with ageing. Research has shown that conditions such as insufficient savings after retirement, poor access to health care, poor dietary intakes and poverty affect the psychological well-being of the elderly. Yet, there is paucity of research on the psychological condition of the elderly in Nigeria. This study examined the psychological well-being of the elderly in Ijumu local government area (LGA) of Kogi State Nigeria. A multi-stage sampling technique was adopted and 1,217 elderly aged $65^{+}$were randomly selected. Psychological well-being was operationalized as whether the respondent experienced good or poor psychological well-being. Data were analysed using descriptive statistics, Chi Square tests and binary logistic regression. The mean age of the elderly was $72.3 \pm 8.4$ years and a higher proportion (53.3\%) experienced good psychological well-being. Age, level of education, current working status and financial assistance from children were the main determinants of good psychological well-being. Specifically, good psychological well-being decreased with increasing age. Also, the odds of having good psychological well-being was lower among those with no education and primary education compared with their counterparts with secondary education or more. Those who were currently working and who received financial assistance from children had better psychological wellbeing. This study showed that effective financial mechanisms need to be put in place by government, NGOs and/or children of the elderly to help improve the financial status of the elderly in order to enhance their psychological well-being.
\end{abstract}

Keywords: psychological well-being, elderly, financial status, Ijumu, Kogi State

\section{Introduction}

The number of older adults is increasing globally and this has become an important concern (Sun \& Lucas, 2011). The proportion of the world's population over 60 years is projected to double from about 11 per cent to 22 
per cent between 2000 and 2050 and expected to increase from 605 million to 2 billion in absolute number over the same period. Low- and Middleincome countries (LMICs), including Nigeria, are projected to experience more of this rapid and drastic demographic change (WHO, 2012). With an estimated population of 140 million in 2006, persons aged 65 years and over constitute 4.3 per cent of the Nigeria population and the absolute number of the elderly in the country has been on the increase (National Population Commission, 2006).

In Africa, particularly Nigeria, many older people reach retirement age after a lifetime of poverty and deprivation, poor access to health care and poor dietary intake. These situations leave them with insufficient personal savings and poor psychological outcomes (Charton \& Rose, 2001; Kimokoti \& Hamer, 2008). The increasing problems associated with ageing are attributed to modernization and its attendant undermining of family structure and lineage systems (Jiloha, 2009). Research has further shown that there is an inverse relationship between modernization and family support for the elderly (Jiloha, 2009; Ting, 2012) and this result in low level of well-being (Asante, 2004). The National Population Commission census report (2006) showed that the number of the elderly is increasing in Nigeria and higher in the rural areas which are already beset by poverty and poor health conditions. Even though studies outside Nigeria have shown that the socio-demographic factors do affect the psychological well-being of the elderly (Patel et al., 2007; Momtaz et al., 2011), the impact of these factors on the psychological well-being of the elderly in Nigeria is not known.

This study examined the prevalence and determinants of good psychological well-being among the elderly in Ijumu LGA, Kogi State, Nigeria. The findings from this study will provide baseline information on the conditions of the elderly in the community. It will also help to facilitate the need for the development of a policy framework for support, interventions and further research on the elderly in Nigeria.

\section{Methodology}

\section{Study Area}

The study was carried out at Ijumu Local Government Area (LGAs) of Kogi State with a population of 119,929 . According to the 2006 census, 53.8 per cent were males and 46.2 per cent were females (NPC, 2006). The community had three administrative districts: Gbede district in the North, Ijumu-central and Ogidi/Ijumu-Oke district in the south. There were 15 political wards in the area with five in Gbede district, four in Ijumu-central district and six in IjumuOke district. There were also 740 enumeration areas in all with 340 in Gbede district, 261 in Ijumu Arin and 149 in Ijumu-Oke (NPC, 2006).

\section{Sample Design}

This was a cross-sectional study of elderly people (65 years and above) residing in Ijumu Local Government Area for at least a year. The study was 
limited to the elderly who had resided in the community for at least one year so as to reduce bias that could occur as a result of influx of older persons who may be visitors.

\section{Sampling Technique}

A multistage sampling technique was adopted. One political ward was randomly selected from each of the 3 districts in the Local Government. Thereafter, simple random sampling technique was used to select one community out of the constituent communities in the ward. House numbering at community level was done with each house having a unique number and 40 houses were randomly selected using table of random numbers. One elderly was interviewed per household and for households having more than one eligible persons, a respondent was picked using lottery method. Based on this, a total of 1217 elderly was interviewed. The data was collected in June 2011.

\section{Measures}

The dependent variable was the psychological well-being of respondents. This was measured using World Health Organization quality of life (QoL) brief (WHOQOL-Brief) questionnaire (The WHOQOL Group, 1995). WHOQOLBrief consists of 6 items, measured on 5-point scale which ranged from 1 to 5 . The score ranged from 4-20. Scores were scaled in a positive direction (that is, the higher scores, the better the psychological wellbeing). The WHOQOLBrief questionnaire has been shown to be a valid measure of quality of life in the elderly (Naumann and Byrne, 2004) with a high internal reliability of 0.86 (Gureje et al., 2008). It is designed as a self-rating instrument that can also be interviewer-administered. The mean psychological well-being score was used to set the cut-off for good and poor psychological well-being. Psychological well-being was regarded as good if the score was greater than the mean score (3.2) and as poor if it was less than or equal to the mean score.

\section{Data analysis}

Descriptive statistics was used to describe the psychological well-being of the elderly. Also, cross-tabulations were used to show the variation in psychological well-being by the socio-demographic variables. Chi-square tests were used to assess the association between the socio-demographic factors and the psychological well-being of the elderly. Thereafter, significant variables from the Chi-square tests were the only factors included for the binary logistic regression. This was used to identify the socio-demographic determinants of good psychological well-being. All analysis were done using SPSS version 15.0 .

\section{Ethical consideration}

Ethical approval for this study was obtained from the Institute for Advanced Medical Research and Training (IMRAT), College of Medicine, University of 
Ibadan, Ibadan Nigeria. The UI/UCH Ethics Committee assigned number for this study is UI/EC/11/0135.

\section{Results}

Table 1 presents the descriptive statistics of the respondents. Their ages ranged from 65 to 106 years with a mean age of $72.3 \pm 8.4$ years. More than half $(53.3 \%)$ had good psychological well-being. A larger proportion were females $(65.2 \%)$ and more than seven out of ten $(71.3 \%)$ were currently married. More than half had no formal education while about 6.6 per cent had higher education. About 70 per cent were Christians and 61 per cent were currently working. A larger proportion of those who were working engaged in agricultural related activities. In addition, more than half $(59.2 \%)$ were in monogamous family and about 96 per cent were Yoruba.

Table 1: Background Characteristics of Respondents

\begin{tabular}{|c|c|c|}
\hline Characteristics & Frequency & Percentage \\
\hline Mean Age & 1217 & $72.3(8.4)$ \\
\hline \multicolumn{3}{|l|}{ Age (years) } \\
\hline $65-69$ & 606 & 49.7 \\
\hline $70-74$ & 243 & 20.0 \\
\hline $75-79$ & 103 & 8.5 \\
\hline $80-84$ & 140 & 11.5 \\
\hline$\geq 85$ & 125 & 10.3 \\
\hline \multicolumn{3}{|l|}{$\overline{\text { Sex }}$} \\
\hline Male & 424 & 34.8 \\
\hline Female & 793 & 65.2 \\
\hline \multicolumn{3}{|l|}{ Marital Status } \\
\hline Never Married & 20 & 1.6 \\
\hline Currently Married & 868 & 71.3 \\
\hline Formerly Married & 329 & 27.1 \\
\hline \multicolumn{3}{|l|}{ Level of Education } \\
\hline No education & 641 & 52.7 \\
\hline Primary & 355 & 29.2 \\
\hline Secondary & 140 & 11.5 \\
\hline Higher & 81 & 6.6 \\
\hline \multicolumn{3}{|l|}{ Religion } \\
\hline Christian & 843 & 69.3 \\
\hline Muslim & 369 & 30.3 \\
\hline Traditional & 5 & 0.4 \\
\hline \multicolumn{3}{|l|}{ Employment Status } \\
\hline Working & 737 & 60.6 \\
\hline Not working & 480 & 39.4 \\
\hline
\end{tabular}




\begin{tabular}{lcc}
\hline Characteristics & Frequency & Percentage \\
\hline Occupation & 11 & \\
Professional & 268 & 1.5 \\
Sales and Services & 45 & 36.4 \\
Skilled manual & 125 & 6.1 \\
Unskilled manual & 288 & 17.0 \\
Agriculture & & 39.0 \\
Family Type & 708 & \\
Monogamy & 489 & 59.2 \\
Polygamy & & 40.8 \\
Ethnic Group & 7 & \\
Hausa & 1,173 & 0.6 \\
Yoruba & 8 & 96.4 \\
Igbo & 29 & 0.7 \\
Others & & 2.3 \\
\hline
\end{tabular}

Note: Number in parenthesis is the standard deviation

\section{Association between socio-demographic characteristics and psychological well-being}

Table 2 shows the socio-demographic distribution of the respondents by psychological well-being. Psychological well-being varied by age group, sex, marital status, level of education, family type, previous work status and current work status. For instance, the proportion of good psychological well-being was highest among respondents who were 65-69 years (61.9\%) and lowest among those aged 85 years and above (27.2\%). Good psychological well-being was higher among females $(57.5 \%)$ and those who were currently married (57.8\%). Further, good psychological well-being increased with increasing level of education. Specifically, about 40 per cent of those with no education had good psychological well-being compared with about two-thirds of those with secondary education or more $(76.9 \%)$. Those who were from monogamous family significantly had better psychological well-being (56.9\%) than those in polygamous family $(48.7 \%)$. Also, the psychological well-being of those who have ever worked and those currently working was better than that of their respective counterparts. A higher proportion of the elderly (55.6\%) who received financial assistance from their children reported good psychological well-being. On the other hand, ever given birth, number of children ever born, religion and ethnicity did not show significant association with psychological well-being. 
Table 2: Distribution of respondents' psychological well-being by sociodemographic characteristics

\begin{tabular}{|c|c|c|c|c|}
\hline \multirow{2}{*}{$\begin{array}{l}\text { Socio-demographic } \\
\text { characteristics }\end{array}$} & \multicolumn{2}{|c|}{$\begin{array}{l}\text { Psychological } \\
\text { well-being }\end{array}$} & \multirow[t]{2}{*}{$\chi^{2}$} & \multirow[t]{2}{*}{ p-value } \\
\hline & Good & Poor & & \\
\hline \multicolumn{5}{|l|}{ Age group (years) } \\
\hline $65-69$ & 61.9 & 38.1 & 59.818 & 0.000 \\
\hline $70-74$ & 51.0 & 49.0 & & \\
\hline $75-79$ & 55.3 & 44.7 & & \\
\hline $80-84$ & 42.1 & 57.9 & & \\
\hline 85 and above & 27.2 & 72.8 & & \\
\hline \multicolumn{5}{|l|}{ Sex } \\
\hline Male & 57.5 & 42.5 & 4.654 & 0.031 \\
\hline Female & 51.1 & 48.9 & & \\
\hline \multicolumn{5}{|l|}{ Marital status } \\
\hline Currently married & 57.8 & 42.2 & 24.695 & 0.000 \\
\hline Others & 42.1 & 57.9 & & \\
\hline \multicolumn{5}{|l|}{ Level of education } \\
\hline None & 41.0 & 59.0 & 96.446 & 0.000 \\
\hline Primary & 60.8 & 39.2 & & \\
\hline Secondary + & 76.9 & 23.1 & & \\
\hline \multicolumn{5}{|l|}{ Ever given birth } \\
\hline Yes & 53.5 & 46.5 & 1.734 & 0.188 \\
\hline No & 28.6 & 71.4 & & \\
\hline \multicolumn{5}{|c|}{ Children ever born (CEB) } \\
\hline 1 & 60.0 & 40.0 & 9.191 & 0.057 \\
\hline 2 & 67.8 & 32.2 & & \\
\hline 3 & 61.8 & 38.2 & & \\
\hline 4 & 51.9 & 48.1 & & \\
\hline 5 and above & 51.7 & 48.3 & & \\
\hline \multicolumn{5}{|l|}{ Religion } \\
\hline Christianity & 54.0 & 46.0 & 0.505 & 0.477 \\
\hline Others & 52.4 & 47.6 & & \\
\hline \multicolumn{5}{|l|}{ Ethnicity } \\
\hline Yoruba & 53.2 & 46.8 & 0.223 & 0.636 \\
\hline Others & 56.8 & 43.2 & & \\
\hline
\end{tabular}




\begin{tabular}{lcccc}
\hline \hline \multirow{2}{*}{$\begin{array}{l}\text { Socio-demographic } \\
\text { characteristics }\end{array}$} & \multicolumn{2}{c}{$\begin{array}{c}\text { Psychological } \\
\text { well-being }\end{array}$} & \multirow{2}{*}{$\chi^{2}$} & p-value \\
& Good & Poor & & \\
\hline \hline Family type & 56.9 & 43.1 & 7.915 & 0.005 \\
$\begin{array}{l}\text { Monogamy } \\
\text { Polygamy }\end{array}$ & 48.7 & 51.3 & & \\
Previous work status & & & & \\
Ever worked & 54.2 & 45.8 & 6.498 & 0.011 \\
Never worked & 38.6 & 61.4 & & \\
Current work status & & & & \\
Currently working & 60.9 & 39.1 & 43.305 & 0.000 \\
Not currently working & 41.7 & 58.3 & & \\
Financial assistance from children & & & \\
Yes & 55.6 & 44.4 & 6.644 & 0.010 \\
No & 46.9 & 53.1 & & \\
\hline \hline
\end{tabular}

Determinants of good psychological well-being

Table 3 shows the determinants of good psychological well-being of the respondents. From the Table, age, level of education, current working status and financial assistance from children were significant determinants of good psychological well-being. The results showed that the odds of having good psychological well-being was higher among elderly who were in the lower age groups compared to those who were $\geq 85$ years. Compared to those with secondary education or more, elderly with no education and those with primary education had lower likelihood of having good psychological well-being $(\mathrm{OR}=0.261$ and 0.506 respectively). Further, those who were currently working were 60.0 per cent more likely to experience good psychological well-being compared to their counterpart who were not currently working. Those who received financial assistance from children were 95.5 per cent more likely to have good psychological well-being compared with those that did not receive financial assistance.

Table 3: Predictors of Psychological good well-being

\begin{tabular}{|c|c|c|c|c|c|}
\hline \multirow{2}{*}{$\begin{array}{c}\text { Socio demographic } \\
\text { variables }\end{array}$} & \multirow{2}{*}{ B } & \multirow{2}{*}{ S.E } & \multirow{2}{*}{ Odds ratio } & \multicolumn{2}{|c|}{ 95\% C.I } \\
\hline & & & & Lower & Upper \\
\hline \multicolumn{6}{|l|}{ Age group (years) } \\
\hline $65-69$ & 0.726 & 0.252 & $2.068 * * *$ & 1.263 & 3.386 \\
\hline
\end{tabular}




\begin{tabular}{|c|c|c|c|c|c|}
\hline \multirow{2}{*}{$\begin{array}{l}\text { Socio demographic } \\
\text { variables }\end{array}$} & \multirow{2}{*}{ B } & \multirow{2}{*}{ S.E } & \multirow{2}{*}{ Odds ratio } & \multicolumn{2}{|c|}{ 95\% C.I } \\
\hline & & & & Lower & Upper \\
\hline $70-74$ & 0.614 & 0.258 & $1.849^{*}$ & 1.115 & 3.066 \\
\hline $75-79$ & 0.847 & 0.297 & $2.332 * * *$ & 1.302 & 4.177 \\
\hline $80-84$ & 0.59 & 0.273 & $1.804^{*}$ & 1.057 & 3.079 \\
\hline$\geq 85(\mathrm{RC})$ & 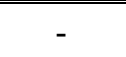 & 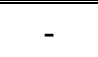 & 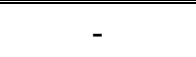 & 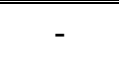 & - \\
\hline \multicolumn{6}{|l|}{ Sex } \\
\hline Female & -0.015 & 0.143 & 0.986 & 0.744 & 1.305 \\
\hline Male (RC) & - & - & - & - & - \\
\hline \multicolumn{6}{|l|}{ Marital status } \\
\hline Currently married & 0.191 & 0.15 & 1.21 & 0.902 & 1.623 \\
\hline Others(RC) & - & - & - & - & - \\
\hline \multicolumn{6}{|l|}{ Level of education } \\
\hline None & -1.344 & 0.204 & $0.261 * * *$ & 0.175 & 0.389 \\
\hline Primary & -0.681 & 0.201 & $0.506^{* * *}$ & 0.341 & 0.751 \\
\hline Secondary+ (RC) & - & - & - & - & - \\
\hline \multicolumn{6}{|l|}{ Family type } \\
\hline Monogamy & 0.043 & 0.131 & 1.044 & 0.808 & 1.35 \\
\hline Polygamy (RC) & - & - & - & - & - \\
\hline \multicolumn{6}{|l|}{ Past working status } \\
\hline Yes & 0.24 & 0.274 & 1.272 & 0.743 & 2.176 \\
\hline No (RC) & - & - & - & - & - \\
\hline \multicolumn{6}{|l|}{ Current working status } \\
\hline Yes & 0.51 & 0.143 & $1.665 * * *$ & 1.258 & 2.203 \\
\hline No (RC) & - & - & - & - & - \\
\hline \multicolumn{6}{|c|}{ Financial assistance from children } \\
\hline Yes & 0.671 & 0.149 & $1.955 * * *$ & 1.46 & 2.619 \\
\hline No (RC) & - & - & - & - & - \\
\hline
\end{tabular}

\section{Discussion}

The current study reports the result of a community-based study of the psychological well-being of the elderly in Ijumu local government area, Kogi State, Nigeria. The mean age of the respondents was $72 \pm 8.4$ years and about 65 per cent were females. More than half of the elderly experienced good 
psychological well-being. The results showed that age, level of education, current working status and financial assistance from children were determinants of good psychological well-being. This study confirms the multifactorial determinants of well-being of the elderly as reported in previous studies (Newsom and Schulz, 1996; Ardelt, 1997; Hickey et al., 2005 and Gureje et al., 2008).

Specifically, this study shows that the psychological well-being of elderly worsens with increasing age. This finding is consistent with outcome of similar studies previously conducted in Nigeria and other parts of the world which found that psychological well-being decreases with increasing age (Johnson and Cooper, 2003; Yuriko and Masumi, 2003; Gureje et al., 2008; Matthew et al., 2010). It is expected that as people grow older, there is tendency for the body mechanisms and organ to also grow old; this can result in frailty in later life and many elderly may not be happy with this.

Further, our study showed that good psychological well-being increased with level of education. That is, the experience of good psychological wellbeing was higher among those with higher level of education. This pattern is expected because those with higher level of education may likely adopt good lifestyle and have access to better nutrition than their counterparts who were less educated. This is consistent with a study which found that those with higher education had better well-being (Sherina et al., 2003). The reason for this is that education provides access to better information on health and this can enhance psychological well-being.

Another factor identified as determinant of good psychological well-being in this study was current working status. The likelihood of having good psychological well-being was higher among elderly who were currently working than those not currently working. The current situation in Nigeria is that the Government does not provide care or support for the elderly. Also, access to good health care in the country is expensive and family support of elderly is already fading away as a result of modernization and economic hardship. Hence, the elderly have to fend for themselves to meet their daily needs in terms of nutrition, shelter, and care provision when they are ill. This therefore put those who are not working at a disadvantaged position. On the other hand, those who were currently working may be able to meet these daily needs in a more convenient way and so have better psychological well-being.

Also, elderly who received financial support from their children had better psychological well-being than those who did not. An explanation for this is that the financial assistance received from children may go a long way in meeting the health, financial and other needs of the elderly. This may therefore enhance their psychological well-being. For instance, a study carried out to explore the relationship between intergenerational social support and the psychological well-being of older Chinese parents found that intergenerational financial support had positive impact on the self-reported health status of the elderly (Zeng, 2008). 
The number of children ever born showed no influence on psychological well-being of the elderly. This is contrary to a study which showed that childlessness has a negative effect on cognitive well-being (Hansen, Slagsvold $\&$ Moum, 2010). This is because childless women reported significantly lower life satisfaction and self-esteem than both mothers with residential children and empty nest mothers (Hansen, Slagsvold \& Moum, 2010). Also, another study which examined the impact of out-migration of adult children on the psychological well-being of older Chinese parents left behind in their rural villages found that the out-migration of children reduced the psychological well-being of their parents, particularly among older fathers (Song, Silverstein \& Li, 2014). Our study however showed that there was no significant difference in the psychological well-being of those who had children and those did not. A plausible explanation for this is that getting support either from family members or other sources may be more important to the psychological well-being of the elderly in this community than having children.

\section{Conclusion}

Our study showed that more than half (53.3\%) of the elderly in this community had good psychological well-being. The determinants of good psychological well-being were age, level of education, current working status, and receipt of financial assistance from children. Based on these findings, we recommend that effective financial mechanisms should be put in place by government and non-governmental organizations (NGOs) for elderly who are neither working nor receiving financial assistance from children. This will help to improve their financial status in the short term as well as enhance their psychological wellbeing in the long run. We also recommend future studies to explore reasons for non-receipt of financial support from children. This will help identify how to enhance and strengthen the social support system for elderly in this community.

\section{References}

Ardelt, M. 1997. Wisdom and life satisfaction in old age. Journal of Gerontology. Series B: Psychological Sciences and Social Sciences. (52): $15-27$.

Asante, K.B. 2004. In defense of age. Daily Graphic Newspaper. Monday, June 28: 7.

Charton, K.E. and Rose, D. 2001. Nutrition among older adults in Africa the situation at the beginning of the millennium. Journal of Nutrition. (131): 245-285.

Gureje, O.; Lola, K.; Ebenezer, A. and Benjamin, O.O. 2008. Determinants of quality of life of elderly Nigerians: results from the Ibadan Study of Ageing. Africa Journal of Medical Sciences. September. 37(3): 239. 
Hickey, A.; Barker, M.; McGee, H. and O’Boyle. C. 2005. Measuring healthrelated quality of life in older patient populations: a review of current approaches. Pharmaco-economics. (23): 971-973.

Jiloha, R.C. Impact of modernization on family and mental health in South Asia. Delhi Psychiatry Journal. 12(1): 42-60.

Johnson, S. and Cooper, C. 2003. The construct validity of the asset stress measure. Stress and Health. (19): 181-85.

Kimokoti, R.W. and Hamer, D.H. 2008. Nutrition, health, and aging in subSaharan Africa. Journal of Nutrition. (66): 611-23.

$\mathrm{Lu}$ Song, Merril Silverstein and Shuzhuo Li. 2014. The Impact of Adult Children's Out-Migration on the Elders' Psychological Well-Being in Rural China: Does Gender Matter? Accessed from http://paa2014. princeton.edu/abstracts/141335.

Mattew, A.; Charles, M.; Honorathy, U.; Jensen, C.; Chriszostom, M.; Salim, A. and Rose, N. 2010. Health status and quality of life among older adults in rural Tanzania. Global health Action Supplement 2.

Momtaz, Y.A.; Ibrahim, R.; Hamid, T.A. and Yahaya, N. 2011. Sociodemographic predictors of elderly's psychological well-being in Malaysia. Aging Mental Health. May. 15(4): 437-45.

National Population Commission (NPC) [Nigeria]. 2009. Final results of 2006 Census. Official Gazette of 2nd February, 2009. Abuja, Nigeria: National Population Commission. 1-327.

Naumann, V.J. and Byrne G.J.A. 2004. WHOQOL-BREF as a measure of quality of life in older patients with depression. International Psychogeriatrics. (16): 159-173.

Newsom, J.T. and Schulz, R. 1996. Social support as a mediator in the relation between functional status and quality of life in older adults. Psychol. Aging. 11: 34-44.

Patel, M.D.; McKevitt, C.; Lawrence, E.; Rudd, A.G. and Wolfe, C.D. 2007. Clinical determinants of long-term quality of life after stroke. Age Ageing. (36): 316-322.

Sherina, M.S.; Nor, A.M.Z. and Shamsul, A.S. 2003. Factors associated with depression among elderly patients in a primary health care clinic in Malaysia. Asia Pacific Family Medicine. (2): 148-52.

Sun, X.; Lucas, H.; Meng, Q. and Zhang, Y. 2011. Associations between living arrangements and health-related quality of life of urban elderly people: a study from China. Quality of Life Research. 20(3): 359-369.

Thomas Hansen, Britt Slagsvold and Torbjorn Moum. 2010. Childlessness and psychological well-being in midlife and old age: an examination of parental status effects across a range of outcomes. Accessed from http://www.hioa.no/asset/3554/1/3554_1.pdf.

Ting, C.A.O. The impacts of modernity on family structure and function: A study among Beijing, Hong Kong and Yunnan families. A thesis submitted in partial fulfillment of the requirements for the degree of Doctor of Philosophy in Social Sciences (Sociology), Lingnan University. 
World Health Organization (WHO). 2012. Interesting facts about ageing

Yi Zeng. 2008. Healthy Longevity in China: Demographic, Socioeconomic, and Psychological Dimensions. Springer Science \& Business Media. Jan 10, 2008 - Health \& Fitness. 245.

Yuriko, D.; Masumi, M. 2003. Factor structure of the 12 item General Health Questionnaire in the Japanese general adult population. Psychiatry and Clinical Neurosciences. (57): 379-83. 